\title{
Microstructural Analysis of Concrete Using Cow Bone Ash for Alkali-Silica Reaction (ASR) Suppression
}

\author{
Ariyo Adanikin $\oplus^{\mathrm{a}, \mathrm{b}^{*}}$, Funsho Falade ${ }^{\mathrm{a}}$, Adewale Olutaiwo ${ }^{\mathrm{a}}$

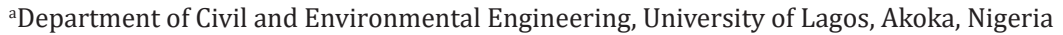 \\ ${ }^{b}$ Department of Civil Engineering, Elizade University, Ilara Mokin, Ondo State, Nigeria \\ *e-mail:nukee02@gmail.com
}

\begin{abstract}
(C) 2020 Authors. This is an open access publication, which can be used, distributed and reproduced in any medium
\end{abstract} according to the Creative Commons CC-BY 4.0 License requiring that the original work has been properly cited.

Received: 21 April 2020/Accepted: 1 July 2020/ Published online: 15 July 2020

This article is published with open access at AGH University of Science and Technology Press

\begin{abstract}
Concrete pavements are prone to microstructural changes and deterioration when exposed to Alkali-Silica Reaction (ASR). ASR results in strength reduction, cracking, spalling and other defects in the concrete if left unchecked. Supplementary Cementitious Materials (SCMs) such as Cow Bone Ash (CBA) however can be used to improve concrete performance, hence its use in this study. Concrete samples were prepared at replacement levels of $0 \%, 5 \%, 10 \%, 15 \%, 20 \%$ and $30 \%$ of cement with Cow Bone Ash. The concrete samples were then subjected to petrographic and Scanning Electron Microscopy (SEM) analysis. Petrographic examination shows that the minimal and least amount of ASR gels and micro cracking were observed at 15\% CBA replacement of cement in the concrete samples. Scanning Electron Microscopy (SEM) analysis shows that changes in the elemental composition of the concrete samples is related to the effect of CBA which enhances adhesion in the concrete. SEM analysis show that, in general, the change in microstructure in the concrete was mainly due to the change in the arrangement of the C-H-S compounds. The microstructure analysis indicates that CBA in concrete influences the densification of the concrete at the transition zone, resulting in a much lower porosity. This results in the concrete having a tightly bound layer that repels ingress of water and thereby inhibiting cracks and gel formation as water is a contributing factor to the ASR in concrete.
\end{abstract}

\section{Keywords:}

petrographic analysis, Scanning Electron Microscopy, Cow Bone Ash, Alkali-Silica Reaction, concrete pavement

\section{INTRODUCTION}

Alkali-silica reactivity has been recognized as a potential source of distress in concrete since the late 1930s because in hardened concrete, aggregates containing reactive silica interact with alkali (sodium oxide and potassium oxide) present in the cement to form expansive alkali silicate gels which disrupt the concrete and thereby forming pattern cracks. The Alkali-Silica Reaction is a type of an internal concrete deterioration which occurs within its entire volume and ASR negative effects are observed in elements such as concrete pavements [1]. ASR produces gels which causes concrete swelling and deterioration when it is exposed to temperature, loadings and humidity. Concrete used in rigid pavements when they deteriorate, compromise the durability and good functioning of the pavements. Sharma [2] found that the osmotic pressure due to alkali-aggregate reaction that occurs on the set cement gel is responsible for concrete defects. The Alkali-Silica Reaction, if unchecked, may cause other problems like pop-outs, spalling etc. and concrete slab may require partial-depth or full-depth repair depending on severity. Factors that promote alkali-aggregate reactions needs to be controlled to keep the pavement away from the ASR menace. If any of these factors are partially or completely removed, ASR will be reduced or will not take place [3]. Hence the use of non-reactive aggregates, low alkali cement and pozzolanas can help in this regard. Alkali-Silica Reaction is a serious problem in concrete when related to rigid pavements considering that once it occurs, no repair methods are available to efficiently and definitely stop the process of ASR and associated damage. Therefore, the best approach is to mitigate it from the onset.

Alkali-Silica Reaction has also been identified on many rigid pavements in the United States of America as seen in its commercial airports Portland Cement Concrete (PCC) pavements in places such as Denver and Colorado Springs in Colorado; 
Hartsfield-Jackson Atlanta International Airport, Georgia. More recently, ASR was identified at the Detroit Metropolitan Airport [4]. Because of the ASR severity, Runway 4L-22R will need to be replaced. Northwest Arkansas Regional Airport (XNA) is in the process of replacing their current 16/34 runway due to ASR. It will cost approximately $\$ 75$ million to construct a temporary runway and reconstruct the 16/34 runway. The runway was constructed in 1998, but has experienced significant distress due to ASR. Distress was manifested through significant slab panel expansion, joint misalignment, heaving, and joint closure. A bridge in Finland required demolition and replacement owing to ASR damage [5]. Also, the concrete containment structures of nuclear power plants in Canada which were designed as crack-free structures by applying biaxial pre-stressing have been damaged due to ASR [6]. Alkali-Silica Reaction has caused problems in at least 46 countries thus, making ASR a serious worldwide problem [7].

Disposal of wastes resulting from myriads of human activities continues to be a problem especially in developing nations, where effective and efficient wastes disposal system is lacking. In the third world countries, the most common and readily available material that can be used to partially replace cement without economic implications are agro and industrial based wastes. These industrial and agricultural wastes are also becoming a health and environmental problem especially in the developing nations where technology for efficient waste disposal is lacking. One such waste product, whose generation runs to millions of tons in Nigeria, are cow bones, from which pulverized bone is obtained [8]. The present disposal system of burning in open sites and indiscriminate dumping on any site does not augur well for the health of human beings and it constitutes environmental hazard.

Supplementary Cementitious Materials (SCMs) such as CBA can be used to improve concrete performance (workability, durability and strength) in its fresh and hardened state as they contribute to the properties of the concrete through hydraulic or pozzolanic activity [9]. Hassan [10] stated that both silica fume and fly ash admixture provide additional benefits to the microstructure homogeneity of hydrated cement paste in concrete. Additionally, the spherical shape of the fly ash and silica fume grains helps to improve the microstructure of cement paste particularly in the Interfacial Transition Zone (ITZ) thereby their importance in concrete as this aids the reduction of ASR gel and crack production. Sarah and Magudeswaran [11] in their study revealed that based on the comparison of the microstructure of concrete mixes, it is clear that the hydration process in the mixes with supplementary materials was different from conventional concrete mix. This was due to the development of C-S-H gel in mixtures with supplementary materials, which is lower than the standard concrete mixture. Investigations by [12] through the Scanning Electron Microscopy (SEM) method shows that ternary blended concrete mix of $70 \%$ of ordinary Portland cement, $20 \%$ of metakaolin and $10 \%$ of microsilica is good for use as a fire resistant structural material. The pozzolanic materials combination when analyzed using SEM showed increasing adhesion and compressive strength hence their ability to inhibit gel and crack formation in the concrete on exposure to fire.

SEM analysis by [13] shows that the dense microstructure of concrete admixed with pozzolanic materials leads to increasing compressive strength of the concrete. Increasing compressive strength of concrete will inhibit the activities of ASR in concrete pavements. Uzbas and Aydin [14] investigated use of fly ash in concrete with Scanning Electron Microscopy and x-ray diffraction. The study revealed that fly ash delivers great performance in concrete because a large amount of silica exists in it and it shows strong pozzolanic property that reaches high strength and increases the durability of concrete. The SEM analysis showed that the usage of fly ash decreases gaps and increases C-S-H which is also a hydration production. When Portland cement was replaced with $10 \%$ fly ash by weight, the microstructure and compressive strength of the concrete improved.

To reduce ASR potential requires understanding the ASR mechanism; properly using tests to identify potentially reactive aggregates; and, if needed, taking steps to minimize the potential for expansion and related cracking using Cow Bone Ash (hereafter, CBA) which this study provides a great insight and understanding to.

\section{DESCRIPTION OF THE RESEARCH}

The concrete mix was designed according to Road Note 4 method of the Department of Scientific and Industrial Research. Natural fine aggregate (sand), cement, CBA aggregates were used. Six different mixes (M1, M2, M3, M4, M5, M6) were prepared at replacement levels of $0 \%, 5 \%, 10 \%$, $15 \%, 20 \%$ and $30 \%$ of cement by Cow Bone Ash in the concrete samples. 18 thin sections ( 3 thin sections from each of the concrete mix samples) were produced in total. Each concrete mix sample was cut using a cutting machine to a square shape of $25 \mathrm{~mm} \times 25 \mathrm{~mm} \times 5 \mathrm{~mm}$ dimensions. The concrete thin section samples were then subjected to petrographic and Scanning Electron Microscopy (SEM) analysis and interpreting the data obtained in light of the study.

\section{Petrographic and Scanning Electron Microscopy (SEM) Analysis}

Petrographic analysis relies on a computer image analysis program designed to quantify the degree of microcracking and the amount of silica gel resulting from ASR. Petrographic analysis helps to identify the nature of deterioration or defects, to determine the degree of damage and to evaluate whether the damage will continue in a concrete sample. Petrographic analysis results are achieved by measuring microcracking, air void structure, aggregate deterioration, and any other possible modes of concrete deterioration due to ASR that are relevant for service life estimation of a rigid road pavement. For the petrographic analysis, the specimens were lessened using an emery cloth and carborundum powder to a thin sheet measured by a micrometer screw gauge to a thickness of about $0.04 \mathrm{~mm}$. The specimens were covered and left for 24 hours after which they were washed, cleaned with spirit, and later with water. Using the Greggory Bottley 
Reflected Light Polarizing microscope, the thin sections slides were then subjected to microscopic examinations. This test was carried out to align with BS 1881-211 [15].

Scanning Electron Microscopy analysis is used to identify and photograph submicroscopic features, and/or determine causes of failure in concrete that may be due to the effect of ASR. It provides information on primary and secondary mineral phases in paste, pores, cracks and micro cavities, morphology of phases, source and deposition area for the mineral phases, identity of tiny micron size mineral phases not visible in the optical microscope. In addition, the SEM analysis gives details on chemical composition of mineral phases, chemical zoning or variation through crystals and through the entire material which are all vital in assessing the effects of the CBA on ASR in the concrete mixes. For the SEM analysis, the specimens $(25 \mathrm{~mm} \times 25 \mathrm{~mm} \times 5 \mathrm{~mm})$ were polished with silicon carbide using a rotating grinder and mounted against a $25 \mathrm{~mm}$ diameter glass plate with epoxy. The samples were cut 2-3 mm thick by using a diamond slicing wheel with propylene glycol coolant being a lubricant to make both sides of the specimen parallel to one another. The specimens were then scooped and polished with silicon carbide using a wheel grinder. Further polishing was conducted on a glass plate with aluminum powder. Post polishing, the specimens were soaked in acetone and placed in an ultrasonic bath. The specimens were then examined using a JEOL JSM-35CF SEM-EDX in the backscatter mode. This test was carried out to align with ASTM C1723 [16].

\section{RESEARCH RESULTS AND ANALYSIS}

\subsection{Petrographic Analysis}

The computer image obtained from the study is as shown in Figures 1-6. The images illustrate the effects of ASR on concrete in a rigid pavement as viewed from prepared thin section slides on the microscope at magnifications ranging from $40 \mathrm{~m}$ to $100 \mathrm{~m}$.

Figure 1 shows petrographic images of the concrete samples at $0 \%$ CBA replacement. High level of gel and crack formation observed. Figure 2 shows petrographic images of the concrete samples at 5\% CBA replacement. ASR gel and bubbles are very visible within the concrete samples. Figure 3 shows petrographic images of the concrete samples at $10 \%$ CBA replacement. Reduced crack levels compared with $0 \%$ and 10\% CBA observed. Microcracking lines also observed within the concrete sample. Figure 4 shows petrographic images of the concrete samples at 15\% CBA replacement. Minimal and least amount of ASR gels and micro cracking were observed. These results can be related to flocculation and discontinuation of gel production that occurs at $15 \%$ CBA production as the CBA has sealed up the cracks and inhibited gel production. Figure 5 shows petrographic images of the concrete samples at 20\% CBA replacement. Increase in gel production observed compared to $15 \%$ CBA addition. Figure 6 shows petrographic images of the concrete samples at 30\% CBA replacement. ASR gel bubbles visible on concrete sample with limited microcracks.

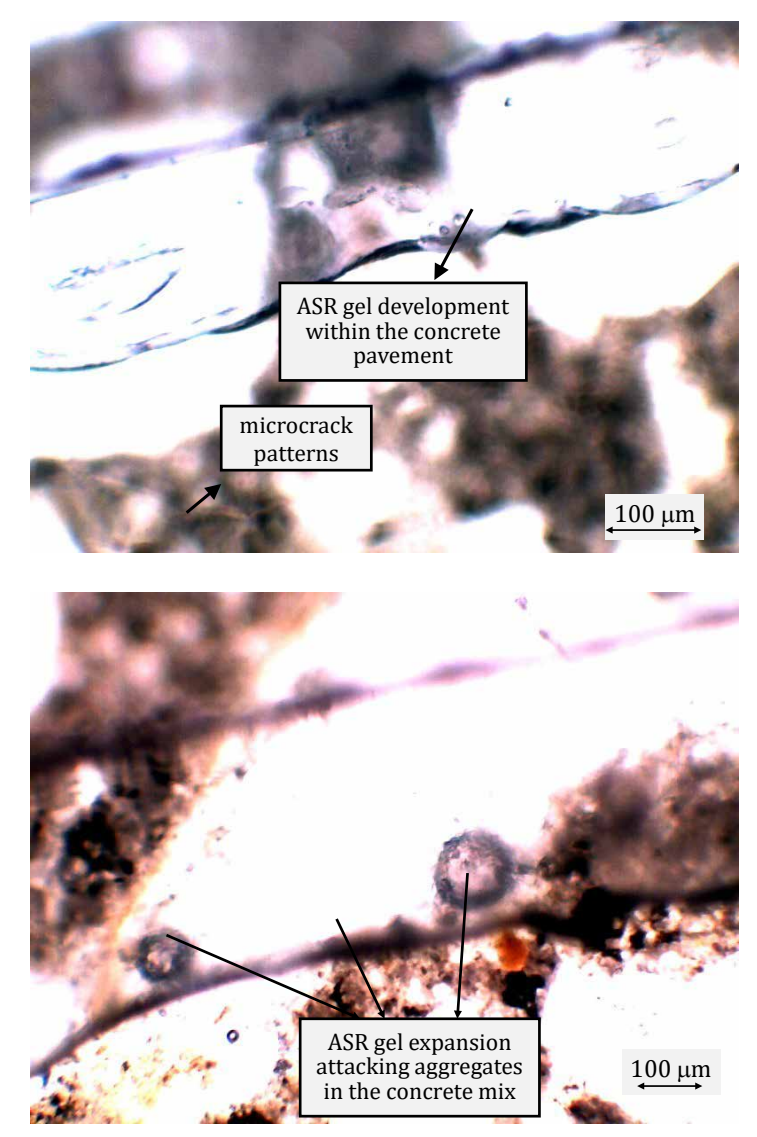

Fig. 1. Petrographic images at $0 \%$ CBA replacement

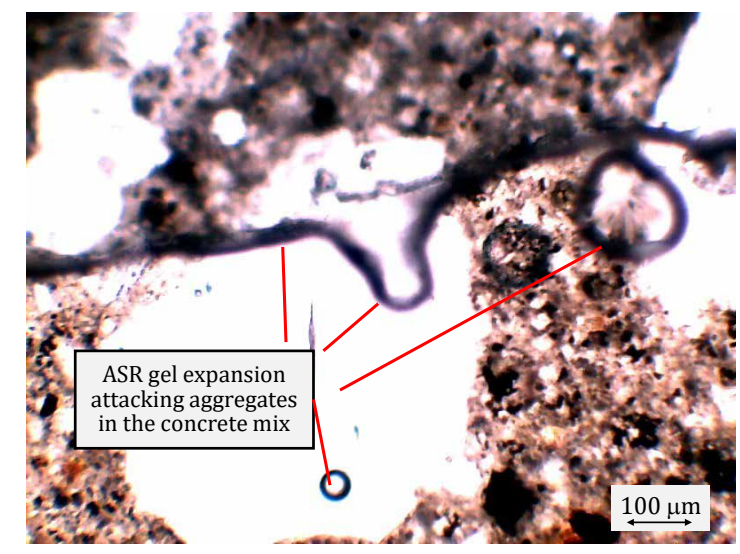

Fig. 2. Petrographic images at 5\% CBA replacement

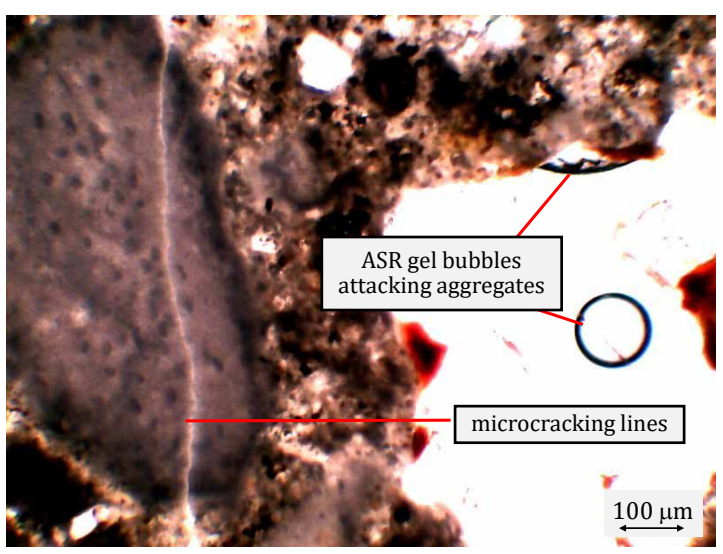

Fig. 3. Petrographic images at $10 \%$ CBA replacement 

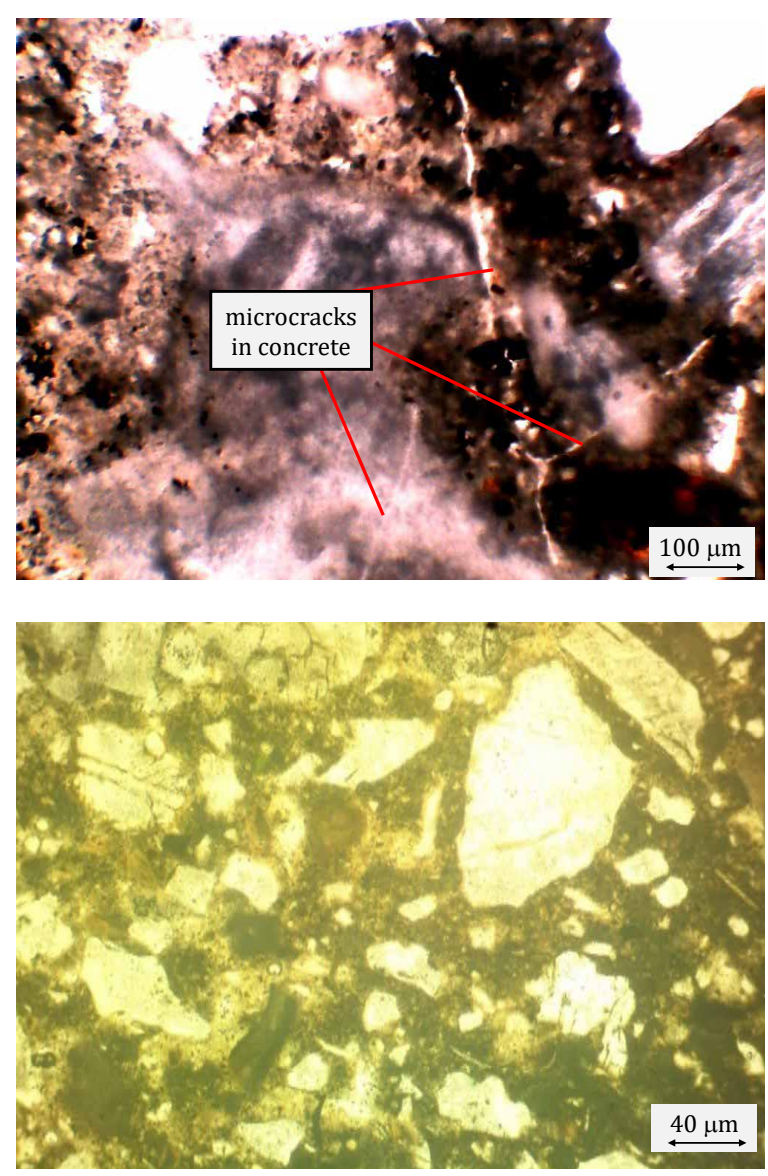

Fig. 4. Petrographic images at $15 \%$ CBA replacement
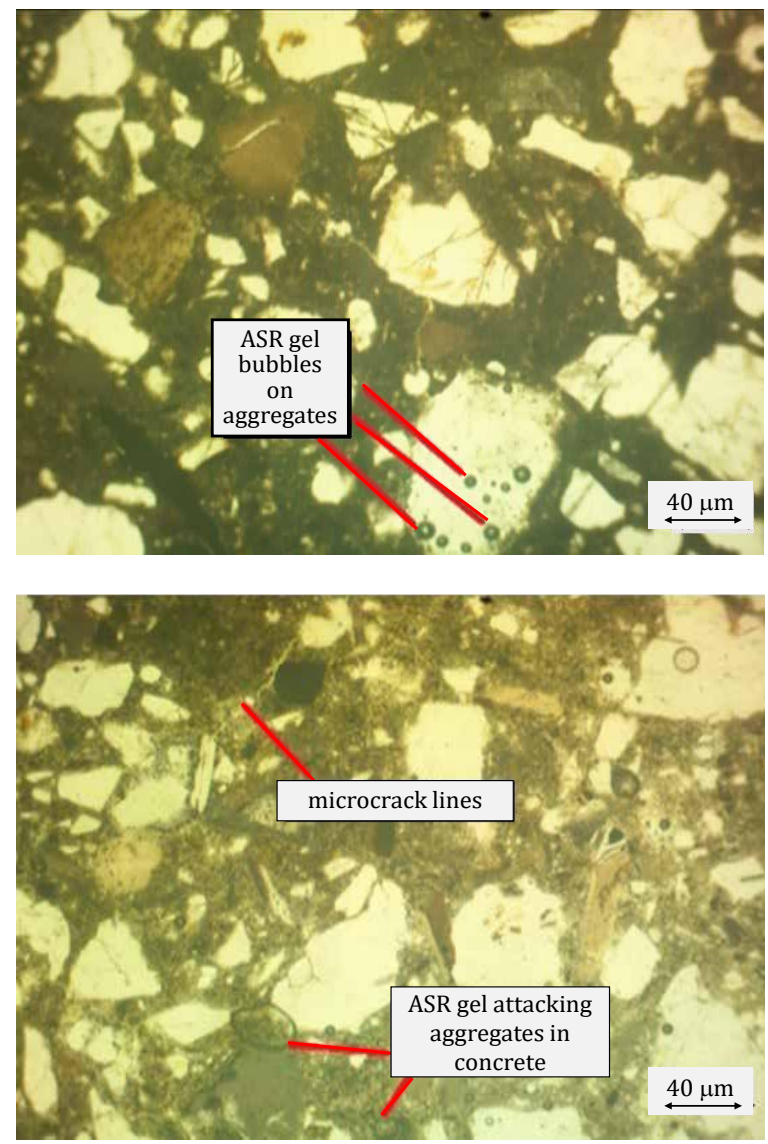

Fig. 5. Petrographic images at $20 \%$ CBA replacement
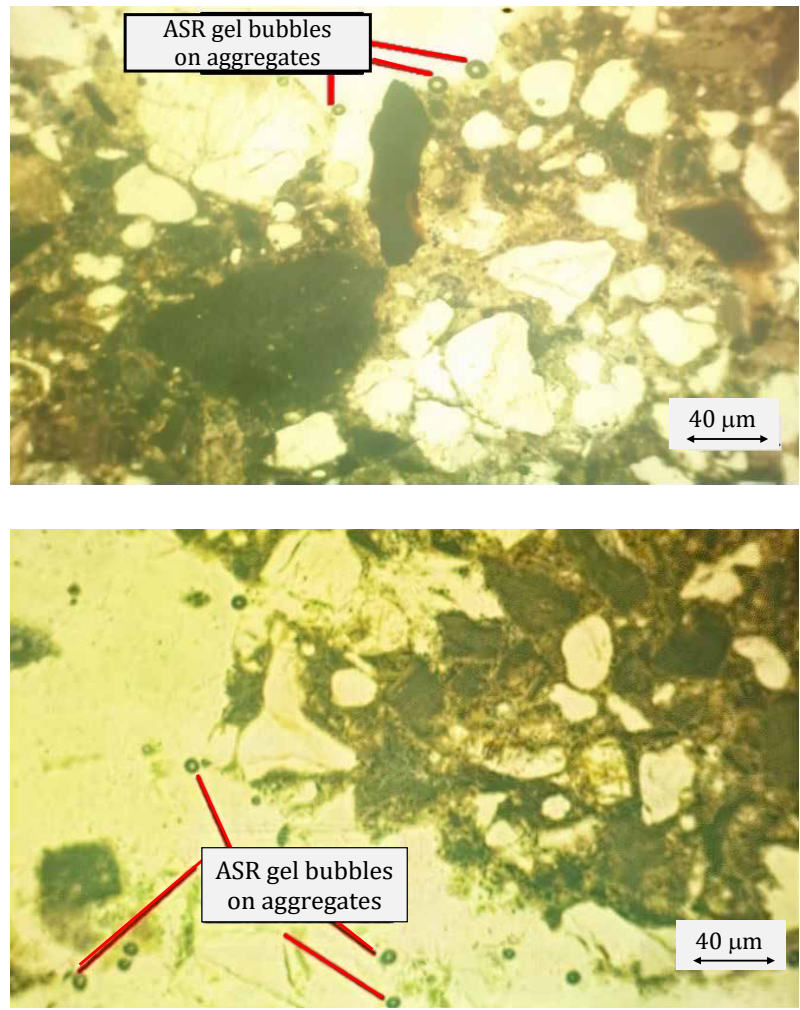

Fig. 6. Petrographic images at 30\% CBA replacement

\subsection{Scanning Electron Microscopy (SEM) Test}

The Backscatter Electron Detector (BSD) and Energy Dispersive X-ray Spectroscopy (EDX) method of Scanning Electron Microscopy (SEM) of the cement-CBA concrete samples were imaged using a focused electron beam that is rastered across the samples surface. This was done to elastically detect scattered electrons that affects the elemental and microstructural characteristics of the concrete samples.

As shown in the Figures 7-12, high levels of calcium content by weight was observed in the concrete samples. The calcium content has a strong impact on the concrete's strength, workability and setting time. The calcium content also strongly impacts the early strength gained by the concrete sample with 0\% CBA. According to [17] the high carbon content in the concrete samples helps to decrease drying shrinkage and increases flexural toughness of concrete samples. Liu et al. [18] also stated that high carbon content in concrete enhances its compressive strength and resistance to cracking. Oxygen is also a prominent element in the concrete samples. This is in consonance with [19] that oxygen is an important binder in concrete structures and without it, rigidity of structures will be compromised. This have affected the properties of the concrete in several ways. Silicon percentages in the concrete samples also varies and plays a prominent role in the concrete's properties as it affects the concrete strength, durability, reduces water absorption capacity and helps it to resist chloride ion penetration [20]. Several other elements exist in the concrete samples at varying atomic concentrations and weight concentrations as shown by the SEM analysis results in Figures 7-12. 


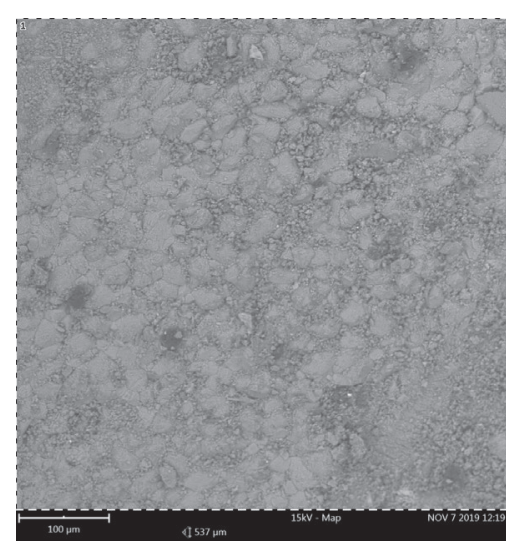

Fig. 7. SEM analysis result at $0 \%$ CBA

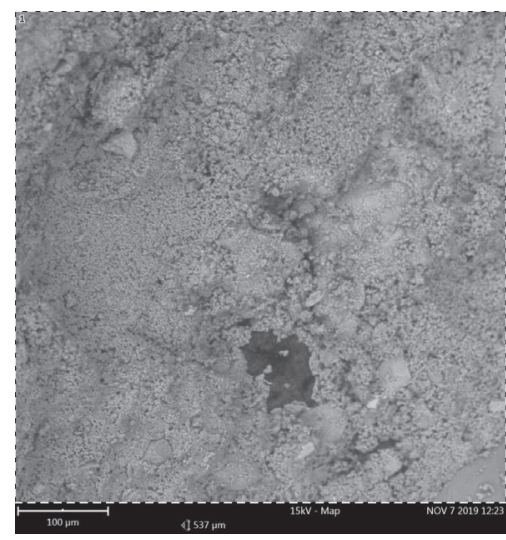

Fig. 8. SEM analysis result at $5 \%$ CBA

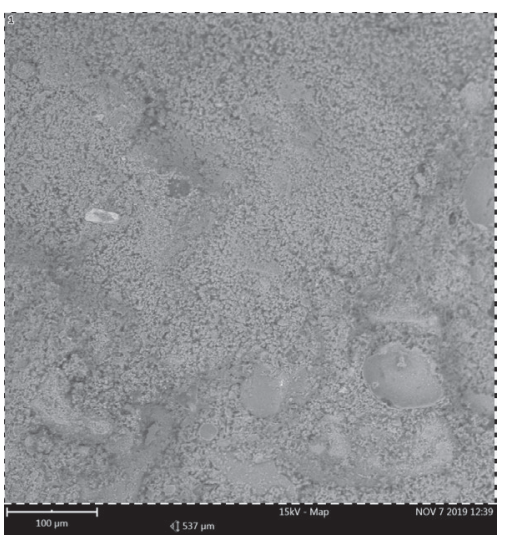

Fig. 9. SEM analysis result at $10 \%$ CBA

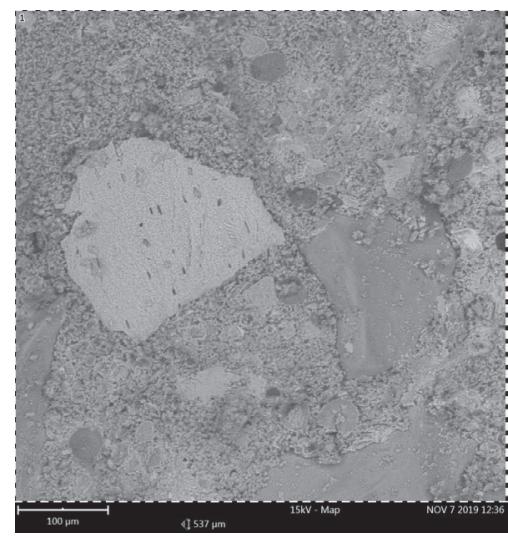

\begin{tabular}{ccc}
\hline $\begin{array}{c}\text { Element } \\
\text { symbol }\end{array}$ & $\begin{array}{c}\text { Atomic } \\
\text { conc. [\%] }\end{array}$ & $\begin{array}{c}\text { Weight } \\
\text { conc. [g] }\end{array}$ \\
\hline $\mathrm{Ca}$ & 43.66 & 59.20 \\
\hline $\mathrm{Si}$ & 12.82 & 12.18 \\
\hline $\mathrm{C}$ & 21.25 & 8.63 \\
\hline $\mathrm{O}$ & 11.73 & 6.35 \\
\hline $\mathrm{P}$ & 3.86 & 4.04 \\
\hline $\mathrm{Zr}$ & 0.81 & 2.51 \\
\hline $\mathrm{Fe}$ & 1.28 & 2.42 \\
\hline $\mathrm{Al}$ & 1.90 & 1.74 \\
\hline $\mathrm{S}$ & 1.58 & 1.72 \\
\hline $\mathrm{Ti}$ & 0.31 & 0.51 \\
\hline $\mathrm{Mg}$ & 0.53 & 0.43 \\
\hline $\mathrm{K}$ & 0.12 & 0.16 \\
\hline $\mathrm{Na}$ & 0.15 & 0.12 \\
\hline & &
\end{tabular}

\begin{tabular}{ccc}
\hline $\begin{array}{c}\text { Element } \\
\text { symbol }\end{array}$ & $\begin{array}{c}\text { Atomic } \\
\text { conc. [\%] }\end{array}$ & $\begin{array}{c}\text { Weight } \\
\text { conc. [g] }\end{array}$ \\
\hline $\mathrm{Ca}$ & 54.05 & 68.79 \\
\hline $\mathrm{Si}$ & 11.17 & 9.97 \\
\hline $\mathrm{C}$ & 15.93 & 6.08 \\
\hline $\mathrm{O}$ & 10.16 & 5.16 \\
\hline $\mathrm{Fe}$ & 1.85 & 3.29 \\
\hline $\mathrm{P}$ & 2.07 & 2.04 \\
\hline $\mathrm{Al}$ & 2.03 & 1.74 \\
\hline $\mathrm{S}$ & 1.18 & 1.20 \\
\hline $\mathrm{Ti}$ & 0.51 & 0.78 \\
\hline $\mathrm{Mg}$ & 0.57 & 0.44 \\
\hline $\mathrm{K}$ & 0.33 & 0.41 \\
\hline $\mathrm{Na}$ & 0.14 & 0.10 \\
\hline & &
\end{tabular}

\begin{tabular}{ccc}
\hline $\begin{array}{c}\text { Element } \\
\text { symbol }\end{array}$ & $\begin{array}{c}\text { Atomic } \\
\text { conc. [\%] }\end{array}$ & $\begin{array}{c}\text { Weight } \\
\text { conc. [g] }\end{array}$ \\
\hline $\mathrm{Ca}$ & 53.24 & 67.85 \\
\hline $\mathrm{Si}$ & 8.43 & 7.52 \\
\hline $\mathrm{C}$ & 17.10 & 6.53 \\
\hline $\mathrm{O}$ & 9.19 & 4.68 \\
\hline $\mathrm{Fe}$ & 1.95 & 3.47 \\
\hline $\mathrm{S}$ & 2.54 & 2.59 \\
\hline $\mathrm{Al}$ & 2.52 & 2.16 \\
\hline $\mathrm{P}$ & 2.07 & 2.04 \\
\hline $\mathrm{K}$ & 1.02 & 1.27 \\
\hline $\mathrm{Cl}$ & 0.76 & 0.86 \\
\hline $\mathrm{Mg}$ & 0.76 & 0.58 \\
\hline $\mathrm{Ti}$ & 0.18 & 0.27 \\
\hline $\mathrm{Na}$ & 0.25 & 0.19 \\
\hline & &
\end{tabular}
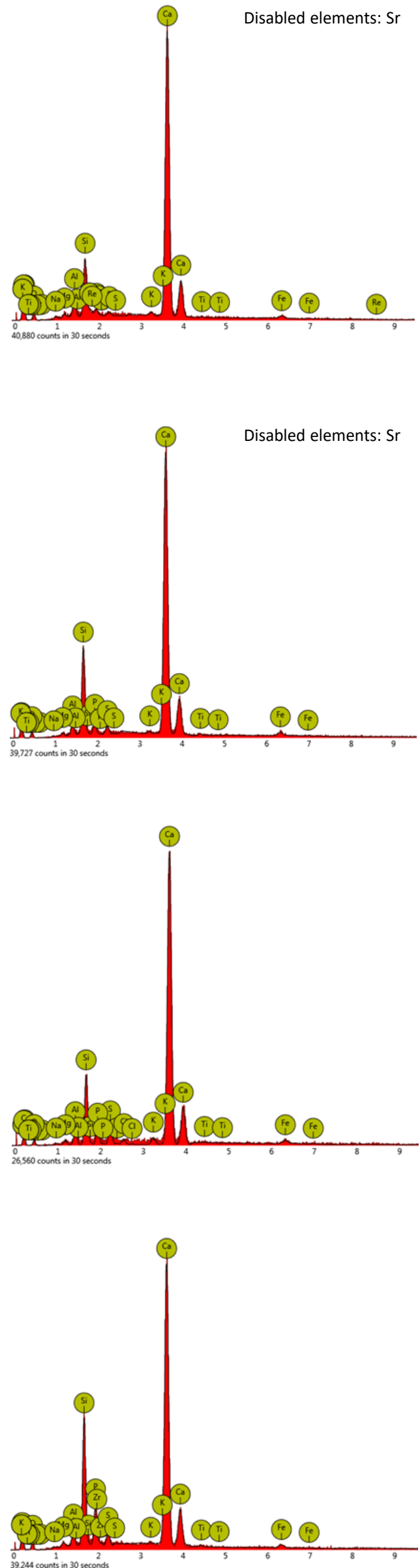

Fig. 10. SEM analysis result at 15\% CBA 


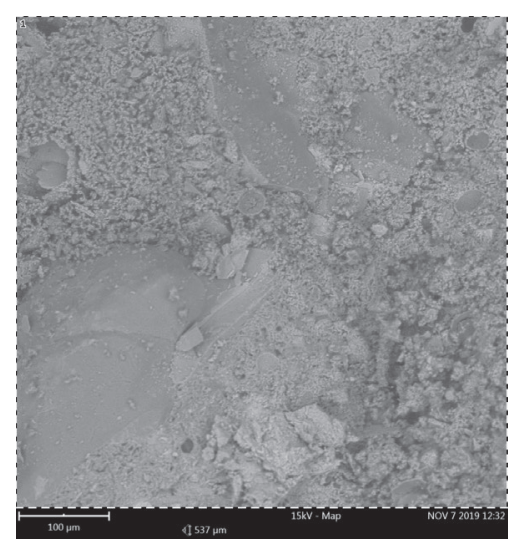

Fig. 11. SEM analysis result at $20 \%$ CBA

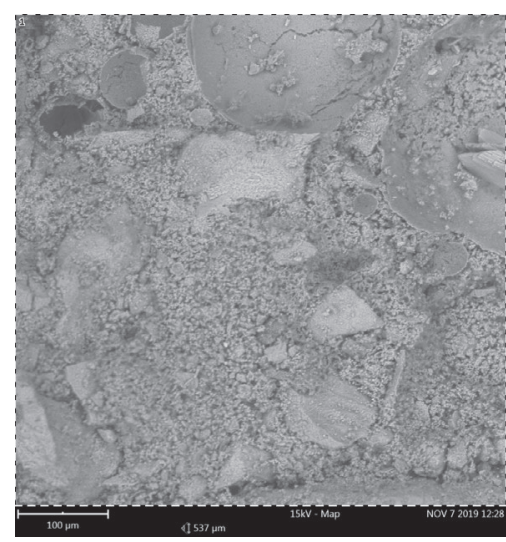

Fig. 12. SEM analysis result at $30 \%$ CBA

\begin{tabular}{ccc}
\hline $\begin{array}{c}\text { Element } \\
\text { symbol }\end{array}$ & $\begin{array}{c}\text { Atomic } \\
\text { conc. [\%] }\end{array}$ & $\begin{array}{c}\text { Weight } \\
\text { conc. [g] }\end{array}$ \\
\hline $\mathrm{Ca}$ & 44.44 & 59.11 \\
\hline $\mathrm{Si}$ & 17.15 & 15.99 \\
\hline $\mathrm{C}$ & 16.09 & 6.41 \\
\hline $\mathrm{O}$ & 11.77 & 6.25 \\
\hline $\mathrm{Fe}$ & 1.79 & 3.32 \\
\hline $\mathrm{P}$ & 3.15 & 3.24 \\
\hline $\mathrm{Al}$ & 1.94 & 1.73 \\
\hline $\mathrm{S}$ & 1.63 & 1.73 \\
\hline $\mathrm{Ti}$ & 0.38 & 0.61 \\
\hline $\mathrm{Mg}$ & 0.66 & 0.54 \\
\hline $\mathrm{K}$ & 0.39 & 0.50 \\
\hline $\mathrm{Cl}$ & 0.27 & 0.32 \\
\hline $\mathrm{Na}$ & 0.34 & 0.26 \\
\hline
\end{tabular}

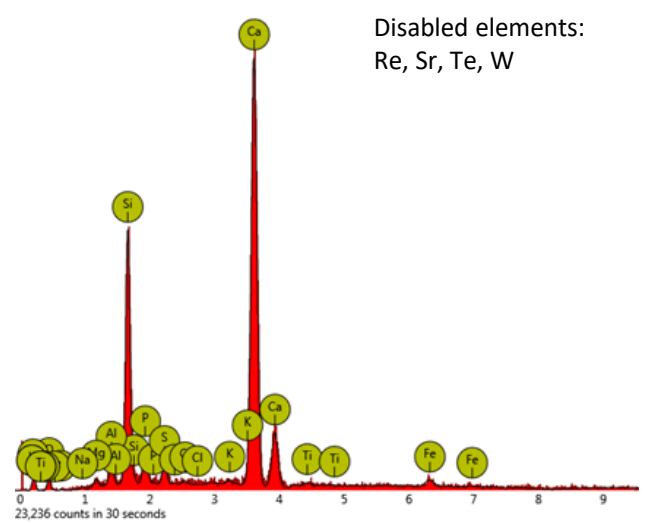

Disabled elements: Re, Sr, Te, W

\section{CONCLUSIONS}

This study reveals that the replacement of cement with Cow Bone Ash of varying percentages $(0 \%, 5 \%, 10 \%, 15 \%, 20 \%$, $30 \%$ ) affects the microstructural behavior of the concrete. The microstructural behavior in turn affects the strength and ASR characteristics of the concrete. Petrographic examination shows that the minimal and least amount of Alkali-Silica Reaction gels and microcracking were observed at 15\% CBA replacement of cement in the concrete samples. These results can be related to the flocculation and discontinuation of gel production that occurs at $15 \%$ CBA production as the CBA has sealed up the cracks and inhibited gel production. Petrographic and SEM analysis reveals that, in the presence of CBA, aggregate reactivity are similar in terms of morphology to traditional AlkaliSilica Reaction gels, however, the amount of gels produced is small, as shown by the compact microstructure and negligible number of microcracks at 15\% CBA replacement in the concrete samples. According to the Scanning Electron Microscopy (SEM) analysis, changes in the elemental composition of the concrete samples are related to the effect of CBA which enhances adhesion in the concrete. The microstructure analysis therefore concludes that pozzolanic reactions activated at $15 \%$ optimum CBA replacement by the presence of Cow Bone Ash (CBA) alters the elemental and microstructural properties of the concrete. This occurs by the release of Calcium Hydroxide $(\mathrm{CH})$ and the production of additional Calcium Silicate Hydrate (C-S-H).

\section{REFERENCES}

[1] Jozwiak-Niedzwiedzka D., Dąbrowski M., Gibas K., Antolik A. \& Glinicki M. (2018). Alkali-Silica Reaction and microstructure of concrete subjected to combined chemical and physical exposure conditions. MATEC Web of Conferences, 163(1-4), 1-10.

[2] Sharma A.K. (2019). Cracks in Pavement Quality Concrete (PQC) - Causes and Remedies. International Advanced Research Journal in Science, Engineering and Technology, 6(10), 40-48.

[3] Zapała-Sławeta Justyna \& Owsiak Z. (2018). The use of lithium compounds for inhibiting alkali-aggregate reaction effects in pavement structures. IOP Conference Series: Materials Science and Engineering, 356, 1-10.

[4] Lawrence E.D. (2015). Flawed concrete found on Detroit Metro Airport runway. Detroit Free Press. Retrieved from: http:// www.freep.com/story/news/local/michigan/wayne/2015/ 01/04/airport-needs-rebuild-million-runway/21236323/ [accessed: 14.10.2019].

[5] Holt E. \& Ferreira M. (2013). Addressing ASR in concrete construction in Finland. In: Nord. Mini Seminar. Alkali Aggregate Reaction in Concrete, Riga, Latvia, 1-15.

[6] Tcherner J. \& Aziz T.S. (2009). Effects of AAR on seismic assessment of nuclear power plants for life extensions. $20^{\text {th }}$ International Conference on Structural Mechanics in Reactor Technology (SMiRT 20), Espoo, Finland, 9-14 August, 2009, (7-1789).

[7] Doran D., Douglas J. \& Pratley R. (2009). Refurbishment and repair in construction. Whittles Publishing, Scotland, UK.

[8] Falade F., Ikponmwosa E. \& Fapohunda C. (2012). Potential of pulverized bone as a pozzolanic material. International Journal of Scientific \& Engineering Research, 3(7), 1-6.

[9] Adanikin A., Falade F.A. \& Olutaiwo A.O. (2019). Efficiency of Cow Bone Ash (CBA) in mitigating alkali silica reaction (ASR) based on accelerated mortar bar test (AMBT) in concrete pavements. UNILAG Faculty of Engineering International Conference on Managing the Environment (FEIC 2019). 15-18 October, 2019, University of Lagos, Nigeria. 
[10] Hassan M.S. (2014). SEM-Backscattered imaging analysis of cementitious composite matrix incorporating mineral admixture. Engineering and Technology Journal, 32(2), 696-703. Doi: 10.1590/s1517-707620170002.0145.

[11] Magudeswaran P. \& Saran A.S. (2017). SEM analysis on sustainable high performance concrete. International Journal of Innovative Research in Science, Engineering and Technology, 6(6), 10237-10246. Doi: 10.15680/IJIRSET.2017.0606016.

[12] Balakrishnaiah D., Balaji K.V.G.D. \& Srinivasa R.P. (2017). Application of SEM method to investigate the cause of effect of elevated temperatures on compressive strength for ternary blended concrete using metakaolin and micro silica. ARPN Journal of Engineering and Applied Sciences, 12(7), 2029-2036.

[13] Kumar S.V., Rajkumar R. \& Umamaheswari N. (2019). Study on mechanical and microstructure properties of concrete prepared using metakaolin, silica fume and manufactured sand. Rasayan Journal of Chemistry, 12(3), 1383-1389. Doi: 10.31788/RJC.2019.1235164

[14] Uzbas B. \& Aydin A.C. (2019). Analysis of fly ash concrete with Scanning Electron Microscopy and X-ray diffraction. Advances in Science and Technology Research Journal, 13(1), 100-110. Doi: 10.12913/22998624/114178.
[15] BS 1881-211 (2016). Testing concrete. Procedure and terminology for the petrographic examination of hardened concrete (British Standard).

[16] ASTM C1723 (2016). Standard guide for examination of hardened concrete using Scanning Electron Microscopy. Retrieved from: https://www.astm.org/Standards/C1723.htm [accessed: 25.07.2019].

[17] Chen P.-W., Fu X. \& Chung D.D.L. (1997). Microstructural and mechanical effects of latex, methylcellulose and silica fume on carbon fiber reinforced cement. ACI Materials Journal, 94(2), 147-155.

[18] Liu D.J., Chen M.J., Xue L. \& He F. (2018). The effect of carbon fiber on concrete compressive strength. Advanced Materials Research, 1145, 106-111.

[19] Kotaro D., Sachiko H., Hideki K. \& Eiji A. (2018). Effects of oxygen pressure and chloride ion concentration on corrosion of Iron in mortar exposed to pressurized humid oxygen gas. Journal of Electrochemical Society, 165(9), 582-589.

[20] Qureshi M. \& Barbhuiya S. (2016). Effects of silica fume on the strength and durability properties of concrete. $1^{\text {st }}$ International Conference on Civil Engineering for Sustainable Development Opportunities and Challenges (CESDOC 2016), 19-21 December, 2016, Guwahati, Assam, India, 117-120. 